\title{
SUBPROBLEM FORMULATIONS BASED ON MAGNETIC FIELD AND SCALAR POTENTIAL VECTORS FOR CORRECTING THIN SHELL MODELS
}

Dang Quoc Vuong*, Bui Minh Dinh

Hanoi University of Science and Technology

ABSTRACT

The propose of this paper is based on subproblem formulations with a magnetic field and scalar potentials to compute and simulate the distribution of fields (magnetic fields, magnetic scalar potentials, eddy currents and Joule power losses) appearing from thin shell models, where it is somewhat difficult to use directly finite element method formulations. The scenario of the method is to couple subproblems in two steps: A subproblem consisting of the stranded inductor and thin shell model is first considered. The following subproblem with actual volumes (including one or two conductive regions) is added to improve errors near edges and corners of the thin shell models. All the steps are independently performed with different meshes and domains, which facilitates meshing and reduces computation time for each sequence.

Keywords: Magnetic field formulations; finite element method; subproblem method; magnetodynamics; eddy currents; magnetic scalar potentials; Joule power losses.

Received: 09/11/2020; Revised: 28/11/2020; Published: 30/11/2020

\section{HIÊU CHỈNH SAI SỐ MÔ HÌNH VỎ MỎNG THÔNG QUA VÉC TƠ TỬ TRƯờnG VÀ TỪ THẾ VÔ HƯớNG BĀNG CÔNG THỨC BÀI TOÁN CON}

Đặng Quốc Vương*, Bùi Minh Định Truòng Đại học Bách khoa Hà Nội

\section{TÓM TĂT}

Mục đích của bài báo này là dựa trên công thức bài toán con với véc tơ từ trường và từ thế vô hướng để tính toán và mô phỏng sự phân bố của trường (từ trường, từ thế vô hướng, dòng điện xoáy và tổn hao công suất) xuất hiện trong mô hình vỏ mỏng dẫn từ, nơi mà được xem như là rất khó có thể áp dụng trực tiếp công thức phương pháp phần tử hữu hạn để thực hiện. Kịch bản của phương pháp cho phép ghép "couple" các bài toán con với hai bước: Một bài toán với mô hình đơn giản các cuộn dây và miền mỏng dẫn từ được xem xét trước. Bài toán tiếp theo bao gồm một hoặc hai miền dần thực tế được đưa vào để cải thiện/hiệu chỉnh sai số xuất hiện gần cạnh và góc của miền mỏng dẫn từ. Tất cả các bước đều được giải độc lập với các lưới và miền khác nhau, điều này tạo thuận lợi cho việc chia giảm được thời gian tính toán cho mỗi một tiến trình.

Từ khóa: Công thức từ truờng; phuoong pháp phần tử hưu hạn; phuoong pháp bài toán con; bài toán tù động; dòng điện xoáy; tù̀ thế vô hướng; tổn hao công suất

Ngày nhận bài: 09/11/2020; Ngày hoàn thiện: 28/11/2020; Ngày đăng: 30/11/2020

\footnotetext{
* Corresponding author. Email: vuong.dangquoc@hust.edu.vn https://doi.org/10.34238/tnu-jst.3767
} 


\section{Introduction}

The direct application of the finite element method formulation for treating magnetodynamic problems, where some of them are conductive thin regions, is somewhat difficult or even impossible [1]. Many researchers have recently presented a thin shell (TS) model in order to overcome this disadvantage [2]. However, this development does not take errors near edges and corners of the TS into account. This makes inaccuracies of the fields (e.g., magnetic fields, eddy currents and joule power losses) increasing with the thickness.

Hence, in this research, subproblem formulations (SPF) based on magnetic field and scalar potentials is presented to correct the TS models, where existing of inaccuracies as mentioned above. The proposed method formulation is considered as in two steps (Figure 1):

- A subproblem (SP) involved with stranded inductors and thin shell regions is first solved.

- The following SP with actual conductive regions that does not include the stranded inductor and TS model anymore is added to improve errors.

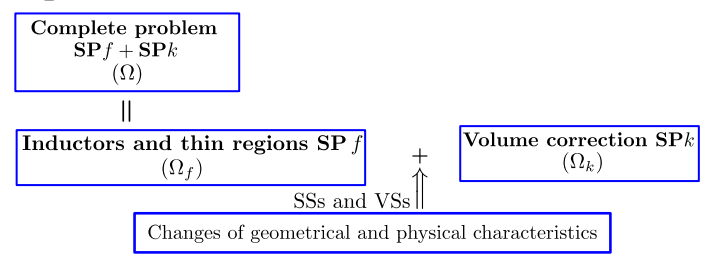

Figure 1. Division of a complete problem into subproblems

The constraints for each SP are volume sources (VSs) or surface sources (SSs), where VSs are changes of permeability and conductivity material of conducting regions, and SSs are the change of interface conditions (ICs) through surfaces from SPs [3]-[7].

As a sequence, the solutions from previous SPs can be considered as VSs or SSs for the current SP. For that, each SP is solved on its own domain and mesh without depending on the previous mesh and domain.

\section{Subproblem method formulation}

\subsection{Canonical magnetodynamic problem}

As presented in [4]-[8], a magnetodynamic problem $q$ at step $q$ of the SPF, is defined in a $\Omega_{q}$, with boundary $\partial \Omega_{q}=\Gamma_{h, q} \cup \Gamma_{e, q}$. Thanks to the set Maxwell's equation, the equations, material behaviors, boundary conditions (BCs) and ICs of SPs are expressed as [6-8]

$$
\begin{array}{r}
\operatorname{curl} \boldsymbol{h}_{q}=\boldsymbol{j}_{q}, \operatorname{div} \boldsymbol{b}_{q}=0, \operatorname{curl} \boldsymbol{e}_{q}=-\boldsymbol{\partial}_{t} \boldsymbol{b}_{q} \\
(1 \mathrm{a}-\mathrm{b}-\mathrm{c}) \\
\boldsymbol{b}_{q}=\mu_{q} \boldsymbol{h}_{q}+\boldsymbol{b}_{s, i}, \boldsymbol{e}_{i}=\sigma_{q}^{-1} \boldsymbol{j}_{i}+\boldsymbol{e}_{s, q}(2 \mathrm{a}-\mathrm{b}) \\
{\left[\boldsymbol{n} \times \boldsymbol{e}_{q}\right]_{\Gamma_{h, q}}=\boldsymbol{k}_{f, q}, \boldsymbol{n} \times\left.\boldsymbol{e}_{q}\right|_{\Gamma_{h, q}}=0,(3 \mathrm{a}-\mathrm{b})}
\end{array}
$$

where $\boldsymbol{h}_{q}$ is the magnetic field, $\boldsymbol{b}_{q}$ is the magnetic flux density, $\boldsymbol{e}_{q}$ is the electric field, $\boldsymbol{j}_{q}$ current density, $\mu_{q}$ is the magnetic permeability, $\sigma_{q}$ is the electric conductivity and $\boldsymbol{n}$ is the unit normal exterior to $\Omega_{q}$.

The fields $\boldsymbol{b}_{s, q}$ and $\boldsymbol{e}_{s, q}$ in (2a-b) are VSs, and $\boldsymbol{k}_{f, q}$ in (3 a) is the SS. In the scope of the SPF, the changes of materials from this region to another region can be expressed (e.g., from $\mu_{f}$ and $\sigma_{f}$ for $\mathrm{SP}_{n}(q=n)$ to $\mu_{n}$ and $\sigma_{n}$ for $\mathrm{SP}_{m}(q=m)$, the source fields $\boldsymbol{b}_{s, i}$ and $\boldsymbol{j}_{s, i}$ are [4]-[7].

$$
\begin{gathered}
\boldsymbol{b}_{s, m}=\left(\mu_{m}-\mu_{n}\right) \boldsymbol{h}_{n}, \\
\boldsymbol{e}_{s, m}=\left(\sigma_{m}^{-1}-\sigma_{n}^{-1}\right) \boldsymbol{j}_{n} .
\end{gathered}
$$

for the total fields to be related by $\boldsymbol{b}_{n}+\boldsymbol{b}_{m}=$ $\mu_{m}\left(\boldsymbol{h}_{m}+\boldsymbol{h}_{n}\right)$ and $\sigma_{m}^{-1}\left(\boldsymbol{j}_{m}+\boldsymbol{j}_{n}\right)$.

\subsection{Magnetic field formulations}

The weak conform of magnetic field formulation of SP $q(q \equiv n)$ is established based on Fraday's law (1c) [6]-[7].

$$
\begin{gathered}
\partial_{t}\left(\mu_{n} \boldsymbol{h}_{n}, \boldsymbol{h}_{n}^{\prime}\right)_{\Omega_{n}}+\left(\sigma_{n}^{-1} \operatorname{curl} \boldsymbol{h}_{n}, \operatorname{curl} \boldsymbol{h}_{n}^{\prime}\right)_{\Omega_{c, n}} \\
+\partial_{t}\left(\boldsymbol{b}_{s, n}, \boldsymbol{h}_{q}^{\prime}\right)_{\Omega_{q}}+\left(\boldsymbol{e}_{s, n}, \operatorname{curl} \boldsymbol{h}_{n}^{\prime}\right)_{\Omega_{n}}+ \\
\left\langle\left[\boldsymbol{n} \times \boldsymbol{e}_{n}\right]_{\gamma_{n}}, \boldsymbol{h}_{n}^{\prime}\right\rangle_{\Gamma_{n}}+\left\langle\boldsymbol{n} \times \boldsymbol{e}_{n}, \boldsymbol{h}_{n}^{\prime}\right\rangle_{\Gamma_{n}-\gamma_{n}} \\
=0, \\
\forall \boldsymbol{h}_{n}^{\prime} \in H_{e, n}^{1}\left(\operatorname{curl}, \Omega_{n}\right) .
\end{gathered}
$$

The general magnetic field $\boldsymbol{h}_{n}$ in (7) can be 
split into two parts, $\boldsymbol{h}_{n}=\boldsymbol{h}_{s, n}+\boldsymbol{h}_{r, n}$, where

$\boldsymbol{h}_{r, q}$ is a reaction magnetic field, which can be defined via

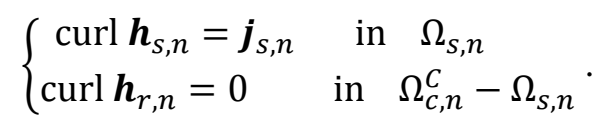

The reaction field $\boldsymbol{h}_{r, i}$ is thus defined via a scalar potential [8] in the non-conducting regions $\Omega_{c, n}^{C}$. The source magnetic field $\boldsymbol{h}_{s, n}$ in (8) is defined via a fixed electric current density in $\Omega_{s, i}$, i.e

$$
\begin{aligned}
\left(\operatorname{curl} \boldsymbol{h}_{s, n}, \operatorname{curl} \boldsymbol{h}_{s, n}^{\prime}\right)_{\Omega_{s, n}} & \\
& =\left(\boldsymbol{j}_{s, n}, \operatorname{curl} \boldsymbol{h}_{s, n}^{\prime}\right)_{\Omega_{s, n}} \\
\forall \boldsymbol{h}_{s, n}^{\prime} & \in H_{e, n}^{1}\left(\operatorname{curl}, \Omega_{s, n}\right),
\end{aligned}
$$

The function space $H_{e, q}^{1}(\ldots)$ in (7) and (9) contains the basis functions $\left(\boldsymbol{h}_{q}\right.$ and $\left.\boldsymbol{h}_{s, q}\right)$ the test function $\left(\boldsymbol{h}_{n}^{\prime}\right.$ and $\left.\boldsymbol{h}_{s, n}^{\prime}\right)$. The notations $(\cdot, \cdot)$ and $\langle\cdot, \cdot\rangle$ are respectively a volume integral in and a surface integral of the product of their vector field arguments. At the discrete level, this space is defined by edge finite elements

\subsubsection{Thin shell formulations for subproblem}

The TS model is defined via the trace discontinuity $\left\langle\left[\boldsymbol{n} \times \boldsymbol{e}_{n}\right]_{\gamma_{n}}, \boldsymbol{h}_{n}^{\prime}\right\rangle_{\Gamma_{n}}$ in (7), i.e. [1]

$$
\begin{gathered}
\left\langle\left[\boldsymbol{n} \times \boldsymbol{e}_{n}\right]_{\gamma_{n}}, \boldsymbol{h}_{q}^{\prime}\right\rangle_{\Gamma_{n}}= \\
\left\langle\mu_{n} \beta_{n} \partial_{t}\left(2 \boldsymbol{h}_{c, n}+\boldsymbol{h}_{d, n}\right), \boldsymbol{h}_{c, n}^{\prime}\right\rangle_{\Gamma_{n}}+ \\
\left\langle\frac { 1 } { 2 } \left[\mu_{n} \beta_{n} \partial_{t}\left(2 \boldsymbol{h}_{c, n}+\boldsymbol{h}_{d, n}\right)\right.\right. \\
\left.\left.\quad+\frac{1}{\sigma_{n} \beta_{n}} \boldsymbol{h}_{d, n}\right], \boldsymbol{h}_{c, n}^{\prime}\right\rangle_{\Gamma_{q}^{+},(10)}
\end{gathered}
$$

where $\boldsymbol{h}_{c, n}$ and $\boldsymbol{h}_{d, n}$ are continuous and discontinuous components of $\boldsymbol{h}_{n}$. The factor $\beta_{n}$ is a factor and is defined via [3]-[7].

2.2.2. Volume correction formulations for subproblem $\mathrm{SP}_{m}(q \equiv m)$

The TS solutions obtained by (10) is now considered as VSs for solving the following subproblem $\mathrm{SP}_{m}(q \equiv m)$ covering a practical volume through the volume integrals $\partial_{t}\left(\boldsymbol{b}_{s, m}, \boldsymbol{h}_{m}^{\prime}\right)_{\Omega_{m}}$ and $\left(\boldsymbol{e}_{s, m}, \operatorname{curl} \boldsymbol{h}_{m}^{\prime}\right)_{\Omega_{m}}$ in (7), where $\boldsymbol{b}_{s, m}$ and $\boldsymbol{e}_{s, m}$ are given in (4a-b).
Hence, the weak formulation $\mathrm{SP}_{m}$ is written as

$$
\begin{aligned}
& \partial_{t}\left(\mu_{m} \boldsymbol{h}_{m}, \boldsymbol{h}_{m}^{\prime}\right)_{\Omega_{m}} \\
& +\left(\sigma_{m}^{-1} \operatorname{curl} \boldsymbol{h}_{m}, \operatorname{curl} \boldsymbol{h}_{m}^{\prime}\right)_{\Omega_{c, n}} \\
& +\partial_{t}\left(\left(\mu_{m}-\mu_{n}\right) \boldsymbol{h}_{n}, \boldsymbol{h}_{m}^{\prime}\right)_{\Omega_{m}} \\
& +\left(\left(\sigma_{m}^{-1}-\sigma_{n}^{-1}\right) \boldsymbol{j}_{n}, \operatorname{curl} \boldsymbol{h}_{m}^{\prime}\right)_{\Omega_{m}} \\
& +\left\langle\boldsymbol{n} \times \boldsymbol{e}_{n}, \boldsymbol{h}_{m}^{\prime}\right\rangle_{\Gamma_{m}}=0, \\
& \quad \forall \boldsymbol{h}_{m}^{\prime} \in H_{e, m}^{1}\left(\operatorname{curl}, \Omega_{2}\right) .
\end{aligned}
$$

At the discrete level, the source fields $\boldsymbol{h}_{n}$ and $\boldsymbol{j}_{n}$ determined in mesh of the $\mathrm{SP}_{n}$ via (10) are now projected in the mesh of $\mathrm{SP}_{m}$ via [5].

$$
\begin{aligned}
& \left(\operatorname{curl} \boldsymbol{h}_{n-m}, \operatorname{curl} \boldsymbol{h}_{m}^{\prime}\right)_{\Omega_{m}}= \\
& \quad\left(\operatorname{curl} \boldsymbol{h}_{n}, \operatorname{curl} \boldsymbol{h}_{m}^{\prime}\right)_{\Omega_{m}}, \\
& \quad \forall \boldsymbol{h}_{m}^{\prime} \in H_{m}^{1}\left(\operatorname{Curl}, \Omega_{m}\right),
\end{aligned}
$$

where $H_{m}^{1}\left(\operatorname{Curl}, \Omega_{m}\right)$ is a gauged curlconform function space for the projected source $m$ and the test function $\boldsymbol{h}_{m}^{\prime}$.

\section{Numerical test}

The application test is a 2-D model based on the team workshop problem 7 consisting of a coil and an aluminum plate [9] (Fig. 2). The coil is imposed by a sinusoidal current with the maximum ampere-turn being 2742AT. The relative permeability and electric conductivity of the aluminum plate are $\mu_{r}=$ $1, \sigma_{r}=35.26 \mathrm{MS} / \mathrm{m}$, respectively. The problem is solved with two cases of frequencies of the $50 \mathrm{~Hz}$ and $200 \mathrm{~Hz}$.

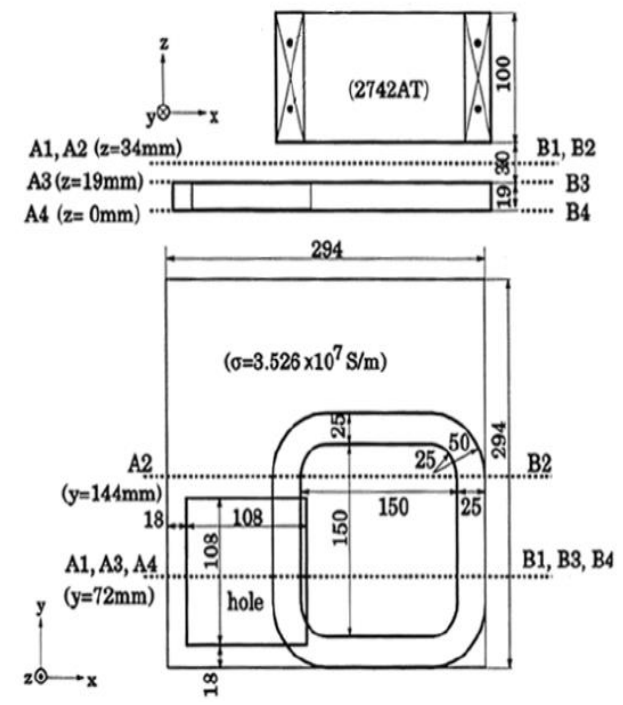

Figure 2. 2-D Geometry of TEAM Problem 7 [9] 


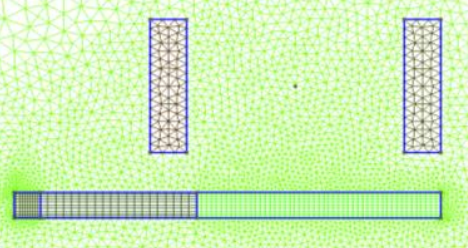

Figure 3. 2-D mesh of the inductor and plate

The 2-D dimensional mesh of the coil and plate with both triangular and rectangular elements is shown in Figure 2.

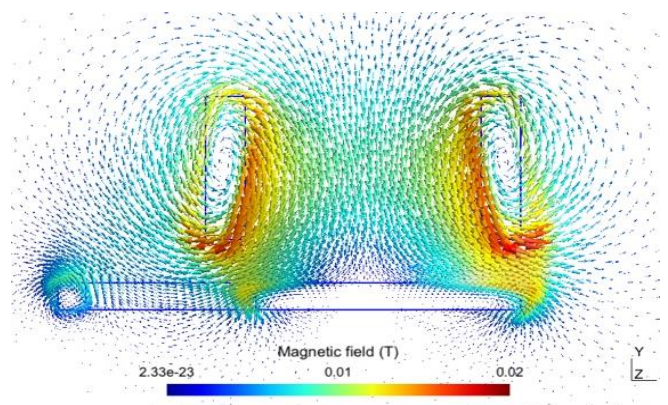

Figure 4. Distribution of magnetic field generated by the imposed sinusoidal current in the stranded inductor (coil), for $f=50 \mathrm{~Hz}$

The distribution of magnetic field created by the imposed electric current in the stranded inductor is presented in Figure 4.

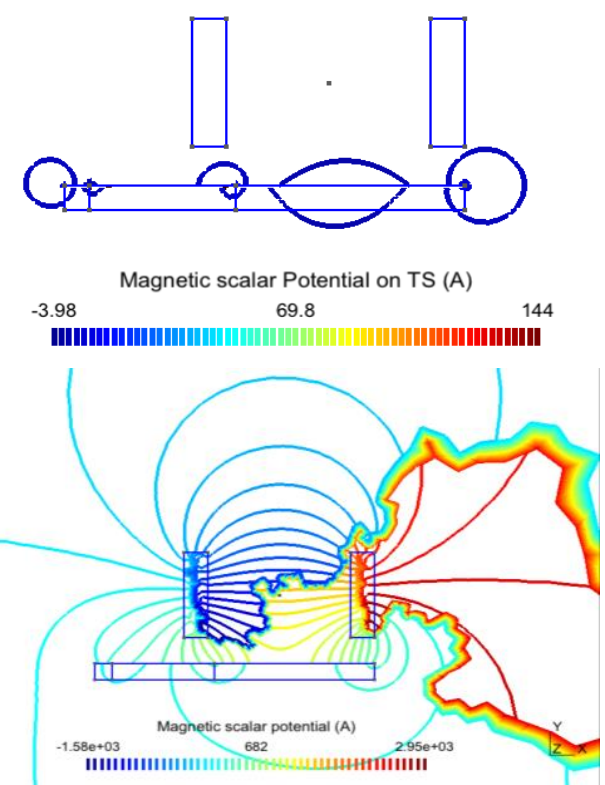

Figure 5. Distribution of magnetic scalar potential for a reduced model with stranded inductor (top) and added TS model (bottom)
The distribution of magnetic scalar potential $\left(\phi_{n}\right)$ for a reduced model due to the electric current flowing in the stranded inductor is pointed out in Figure 5 (top). The discontinuity component $\left(\Delta \phi_{n}\right)$ of the field presented at the TS model is different from zero and equal to zero on both side of TS model (Figure 5, bottom).
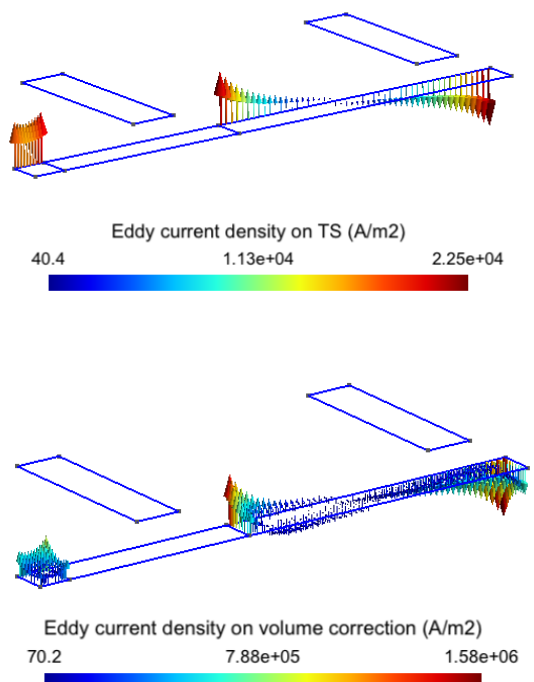

Figure 6. Map of the TS solution (top) and volume correction (bottom), along the plate, for frequency of $50 \mathrm{~Hz}$

The simulated solutions on the eddy current density along the plate are shown in Figure 6. The inaccuracy on the TS model (Figure 6, top) is improved by the volume correction (Figure 6 , bottom). The mean error between two solutions on the eddy current is approximately $45 \%$.

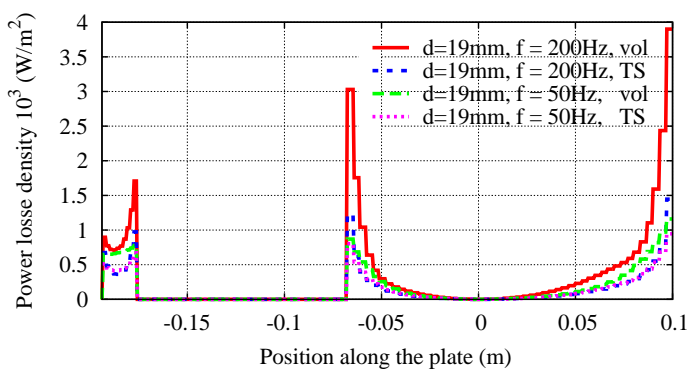

Figure 7. The cut lines of distribution of power loss density along the plate, for the different frequencies

The cut lines of power loss distribution for different frequencies $(50 \mathrm{~Hz}$ and $200 \mathrm{~Hz}$ ) 
along the line A3-B3 (Figure 1) is depicted in Figure 7.

For a frequency $f=200 \mathrm{~Hz}$, the significant error on the eddy current near edges and corner of the plate (cut line A3-B3) reaches $60.5 \%$, and being lower than $20 \%$ for $f=50$ $\mathrm{Hz}$. At the middle of the plate, the error is lower and is equal to zero through the hole. This is also demonstrated that there is a very good simulation on the developed magnetic filed formulation of SPF.

\section{Conclusions}

All the steps of the SPF have been successfully with the magnetic field formulations. The practical test problem (TEAM problem 7 [9]) has been applied to modelize the distribution of magnetic fields, magnetic scalar potentials, eddy currents and Joule power losses due to the excited electric current following in the coil. The obtained results are also a good step for manufacturers to see that where the hotpot appears in the conducting regions proposed in the future work.

The source-codes of the SPF have been developed by author and two professors (Prof. Patrick Dular and Christophe Geuzaine, University of Liege, Belgium). The simulated results have been performed via softwares Gmsh (http://gmsh.info/) and Getdp (http://getdp.info/) proposed by Prof. Christophe Geuzaine and Prof. Patrick Dular.

\section{REFERENCES}

[1]. S. Koruglu, P. Sergeant, R. V. Sabarieqo, V. Q. Dang, and M. De Wulf, "Influence of contact resistance on shielding efficiency of shielding gutters for high-voltage cables," IET Electric
Power Applications, vol. 5, no. 9, pp. 715-720, 2011

[2]. V. Q. Dang, P. Dular, R. V. Sabariego, L. Krähenbühl, and C. Geuzaine, "Subproblem approach for Thin Shell Dual Finite Element Formulations," IEEE Transactions on Magnetics, vol. 48, no. 2, pp. 407-410, 2012.

[3]. P. Dular, V. Q. Dang, R. V. Sabariego, L. Krähenbühl, and C. Geuzaine, "Correction of thin shell finite element magnetic models via a subproblem method," IEEE Transactions on Magnetics, vol. 47, no. 5, pp. 158-161, 2011.

[4]. Velasco, F. Henrotte, and C. Geuzaine, "FiniteElement Modeling of Thin Conductors in Frequency Domain," IEEE Transactions on Magnetics, vol. 56, no. 4, pp. 1-4, 2020, doi: 10.1109/TMAG.2019.2955514.

[5]. Q. V. Dang, "Improved error of electromagnetic shielding problems by a two-process coupling subproblem technique," Science \& Technology Development Journal, vol. 23, no. 2, pp. 524527, 2020, doi: 10.32508/stdj.v23i2.2054.

[6]. V. Q. Dang, P. Dular, R. V. Sabariego, L. Krähenbühl, and C. Geuzaine, "Subproblem Approach for Modelding Multiply Connected Thin Regions with an h-Conformal Magnetodynamic Finite Element Formulation," EPJ AP., vol. 64, no. 2, pp. 24516p1-24516p7, 2013.

[7]. Q. V. Vuong, "Robust Correction Procedure for Accurate Thin Shell Models via a Perturbation Technique," Engineering, Technology \& Applied Science Research, vol. 10, no. 3, pp. 5832-5836, 2020.

[8]. Q. V. Dang, "Modeling of Magnetic fields and Eddy current losses in Electromagnetic Screens by a Subproblem Method", TNU Journal of Science and Technology, vol. 192, no. 16, pp. 712, 2018.

[9]. G. Kovacs, and M. Kuczmann, Solution of the TEAM workshop problem No.7 by the finite Element Method, International Compumag Society Board, 2011, pp. 1-15. 